\title{
FOLIAR POTASSIUM FERTILISER HELPS TO INCREASE KERNEL OIL CONTENT IN STYRAX TONKINENSIS, A NON- FOOD FEEDSTOCK
}

\author{
Zhang $Z^{1,2}$, Qikui Wu ${ }^{1,3}$, Ying Luo ${ }^{1,4}$, Xiaojun Wang ${ }^{1} \&$ Fangyuan Yu ${ }^{1, *}$ \\ ${ }^{1}$ Collaborative Innovation Center of Sustainable Forestry in Southern China, College of Forest Science, Nanjing Forestry \\ University, Nanjing, Jiangsu 210037, China \\ ${ }^{2}$ State Key Laboratory of Tree Genetics and Breeding $\mathcal{E}$ Key Laboratory of Tree Breeding and Cultivation, State Forestry \\ Administration, Research Institute of Forestry, Chinese Academy of Forestry, Haidian, Beijing 100091, China \\ ${ }^{3}$ State Forestry and Grassland Administration Key Laboratory of Silviculture in downstream areas of the Yellow River, \\ College of Forestry, Shandong Agricultural University, Tai'an, Shandong 271018, China \\ ${ }^{4}$ Hunan Quality Inspection and Testing Center for Forestry Products, Changsha, Hunan 410007, China
}

*fyyu@njfu.edu.cn

Received May 2020; accepted December 2020

\begin{abstract}
Styrax tonkinensis is a biofuel feedstock with potential value to produce a considerable amount of non-edible oil. Whether exogenous potassium (K) spray can boost $S$. tonkinensis seed oil content was tested. A total amount of $0.5 \mathrm{~g} \mathrm{~L}^{-1}(\mathrm{~K} 1)$ and $4 \mathrm{~g} \mathrm{~L}^{-1}(\mathrm{~K} 2)$ potassium D-gluconate was applied exogenously as foliar fertilisers during fruit maturation, compared with control (CK, water) and gluconate control $\left(0.676 \mathrm{~mL} \mathrm{~L}^{-1}(\mathrm{G} 1)\right.$ and $5.403 \mathrm{~mL} \mathrm{~L}^{-1}$ (G2) D-gluconic acid). Higher average values of net photosynthesis rate and elevated peak values of chlorophyll $\mathrm{a} / \mathrm{b}$ and chlorophyll $(\mathrm{a}+\mathrm{b}) /$ carotenoid were found in the leaves that received the $\mathrm{K}$ applications. The superior photosynthesis behaviour was accompanied by a dry mass increment in kernel ( $30.1 \%$ for K1, 52.4\% for K2) at 137 days after flowering (DAF). Under K treatments, lipid assembled more slowly during 37-77 DAF. The final oil concentration in kernels was similar in CK and K applications. In CK, dynamic acetyl-CoA carboxylase (ACCase) activity followed an M-shaped trend, whereas in other treatments, it only had one single peak at 57 or 77 DAF. Major increases in lipid yield per kernel were identified. The collective results highlighted the role of foliar potassium, which, in suitable concentration, may boost the total oil content per kernel in S. tonkinensis.
\end{abstract}

Keywords: Foliar fertiliser, kernel maturation, lipid biosynthesis, potassium D-gluconate, Styrax tonkinensis

\section{INTRODUCTION}

Rapid industrialisation and urbanisation are now boosting global feedstock consumption and accelerating the depletion of naturally occurring fossil fuels. In the last 50 years, an increase of fossil fuel consumption ( $5 \%$ per year) has been witnessed (Harwood et al. 2017). As an alternative energy, renewable biodiesel is recognised as a way to mitigate the worldwide energy and environmental challenges (Xiong et al. 2018). In developing countries like China, because of population growth and food security, limited arable land is used for grain planting. Thus, the application of crop feedstocks, i.e., oilseed rape (Brassica napus), soybean (Glycine max) and maize (Zea mays) to the biodiesel industry would be impractical (Xiong et al. 2018). Therefore, forest-based biomass, especially from woody oil plants, is attractive to Chinese researchers and policymakers. Moreover, manipulating the yield and quality of oil produced by these bioenergy tree species has become an important research focus in recent years (Harwood et al. 2017).

Styrax tonkinensis is widely distributed in Vietnam, Laos and the southern provinces of China. It is known for its fragrant stemextracted resin, medicinal properties, ornamental application and timber utilisation (Pinyopusarerk 1994, Hieu et al. 2011, Xu \& Yu 2015, Matsuo et al. 2016, Wu et al. 2020a). The oilseed is also famous for its rich lipid production and capability for fast growth (Shi et al. 2013). Thus, many Chinese agronomists and researchers have recognised $S$. tonkinensis as a promising woody plant to be utilised in the renewable diesel industry (Chen et al. 2015). 
Extensive work has been carried out to broaden and deepen the understanding of the mechanism that regulates lipid synthesis pathway in general (Liu et al. 2014). As observed in the model plant, Arabidopsis thaliana, the quantitative oil content trait in seeds is controlled by a complicated transcriptional and enzymatic regulatory network (Wu et al. 2006). The substrate partitioning among all primary and secondary carbon reserves, and the deposit and transfer of maternal-derived precursors may also affect the embryonic oil bioaccumulation in plant seeds (Baud \& Lepiniec 2010, Liu et al. 2014). In $S$. tonkinensis, the seed oil yield has been shown to be influenced by the carbon competition between starch and lipid synthesis in kernels, and the maternal photosynthesis status in the pericarps (Zhang et al. 2017, Zhang et al. 2018a).

Previous investigations confirm that the oil accumulation rate declines during the midlate stage of S. tonkinensis seed filling (80-120 days after flowering (DAF), as shown by in vitro physiological and oil body ultrastructural evidences (Zhang et al. 2017, Zhang et al. 2018b). Moreover, the potassium concentration plateau in S. tonkinensis kernels was observed between 80 and $120 \mathrm{DAF}$, which overlapped with the 40 day reduction in the oil accumulation rate. Furthermore, the potassium concentration showed a significant correlation with crude oil $\left(\mathrm{r}^{2}=0.850, \mathrm{p}<0.01\right)$ and total fatty acid $\left(\mathrm{r}^{2}=\right.$ $0.859, \mathrm{p}<0.01)($ Wu et al. 2019).

Potassium is an essential macronutrient for plant growth and development (Gotore et al. 2014, Kamel et al. 2016). It plays a pivotal role in many plant physiological processes, affecting photosynthesis, photosynthate transport in phloem, enzyme activation, protein synthesis, osmoregulation, plant-water relation and stress resistance (Marschner 2012). Field experiments have shown that the use of $\mathrm{K}$ would influence seed yield and oil contents in canola and cotton seeds (Kamel et al. 2016).

In this study, the effect of foliar potassium on S. tonkinensis kernel development was investigated. Based on the significant positive correlation between oil and $\mathrm{K}$ concentration, it was hypothesised that exogenous foliar $\mathrm{K}$ application could increase kernel oil content. Mainly, the aims of the study are to answer the following two questions: (1) Would foliar K treatments affect potassium concentration in the developing S. tonkinensis kernel? (2) Would the seed oil accumulation process, kernel oil content and composition be influenced by $\mathrm{K}$ application? Since upregulation of seed oil yield through genetic manipulation might not be as effective as originally expected, data from the present study may provide a non-genetic-based method for boosting $S$. tonkinensis seed oil yield in a much simpler way (Ohlrogge \& Jaworski 1997).

\section{MATERIALS AND METHODS}

\section{Plant materials}

Two-year-old S. tonkinensis seedlings were purchased from Jishui (Jiangxi Province, PR China) and planted in 2011 on the east side of Hewangba Reservoir, Luhe District, Nanjing, PR China $\left(32^{\circ} 54^{\prime} \mathrm{N}, 118^{\circ} 50^{\prime} \mathrm{E}\right)$, and the trees grew under natural conditions. Open pollination occurred after the plants' juvenile phase ended in 2012. In late May 2016, three blocks $(40 \mathrm{~m} \times 50 \mathrm{~m})$ were randomly chosen in the field. Ninety trees with similar height $(3.2 \pm 0.5 \mathrm{~m})$ and number of flowers $(3320 \pm 911)$ were tagged in these blocks (30 trees each) for in vivo treatment and further sampling. The highest/lowest temperatures and cumulative monthly precipitation from April to October in Luhe District were recorded (Figure S1).

\section{Plant foliar fertilisers}

To rule out the influence of inorganic anions, 0.5 and $4 \mathrm{~g} \mathrm{~L}^{-1}$ potassium D-gluconate solution were used as foliar potassium fertiliser. These two treatments were assigned as K1 and K2 respectively. Then, because of the possible effects of gluconate on this experiment, 0.676 and $5.403 \mathrm{~mL} \mathrm{~L}^{-1} \mathrm{D}$-gluconic acid solution were used as the gluconate control. These two treatments were assigned as G1 and G2. The control plants were only treated with water (CK). Polysorbate was added as a surfactant to promote $\mathrm{K}$ absorption. Its final concentration in the foliar fertiliser was $4 \%$. The potassium and gluconate concentration in each treatment are given in Table S1.

\section{Fertiliser spray experiments}

The fertiliser was applied onto the whole tree crown using a manual sprayer (total volume of $16 \mathrm{~L}$, spray rate of $\left.15 \mathrm{~mL} \mathrm{~m}^{-2} \mathrm{~s}^{-1}\right)$. The application 
was always performed in the morning (6:30 to 8:30 a.m.) right after sampling (on 38, 58, 78, 98 and 118 DAF). A randomised complete block design was performed in this study. A similar treatment (K1, K2, G1, G2 or CK) was applied on trees with similar growth conditions in the field $(\mathrm{n}=18)$. Approximately $900 \mathrm{~mL}$ foliar liquid fertiliser was used on each sampled tree, corresponding approximately to a dose of 0.075 or $0.599 \mathrm{~g}$ potassium per tree in foliar $\mathrm{K}$ treatment, and 0.377 or $3.015 \mathrm{~g}$ D-gluconic acid per tree in the gluconate control treatment.

\section{Photosynthetic activity}

Photosynthetic parameters were measured in the field on 26 July (57 DAF) using a portable photosynthesis system. Measurements were performed in the morning (08:00 to 11:30 a.m.). The leaves remained attached to the stem during measurement. The chamber temperature was kept at $24.9 \pm 0.6{ }^{\circ} \mathrm{C}$, the intensity of light $1000 \mu \mathrm{mol} \mathrm{m} \mathrm{s}^{-1} \mathrm{~s}^{-1}$, ambient $\mathrm{CO}_{2}$ concentration about $400 \mu \mathrm{mol} \mathrm{mol}^{-1}$, and humidity $31.7 \pm 0.9 \%$. Data of each treatment represented the means obtained from three plants in three blocks. The values of photosynthetically active radiation (PAR) were $1045 \pm 220$ (CK), $1204 \pm 147$ (K1), $1192 \pm 69(\mathrm{~K} 2), 1155 \pm 99(\mathrm{G} 1)$ and $1163 \pm 61$ (G2) $\mu \mathrm{mol} \mathrm{m} \mathrm{m}^{-2} \mathrm{~s}^{-1}$, respectively.

\section{Chlorophyll content of leaves}

The pigment content of leaves was determined using leaf discs. The chlorophyll a $(\mathrm{Chl} \mathrm{a})$, chlorophyll b (Chl b) and carotenoid (Car) contents were measured in the samples upon extraction in buffered aqueous $80 \%$ acetone (Porra 2005). Absorbance at 644, 663 and $470 \mathrm{~nm}$ of the supernatant was measured with a spectrophotometer. Leaves from all treatments were rinsed in distilled water prior to analysis.

\section{Kernel dry mass measurements}

For each treatment, fresh fruits were harvested at approximately the same tree height. Fruit samples were hand-picked randomly in different crown directions from 6 July (37 DAF) to 14 October (137 DAF), with a 19-day interval between each harvest. Drupes were sealed in plastic bags immediately and embedded in an insulation ice box $\left(-10^{\circ} \mathrm{C}\right)$. Kernels, from three replicates of 30 randomly selected fruit, were dried at $70{ }^{\circ} \mathrm{C}$ for 72 hours and weighed (dry matter $(\mathrm{DM})$. The remaining fruits were frozen in liquid nitrogen and stored at $-80{ }^{\circ} \mathrm{C}$ for later analyses.

\section{Lipid extraction and determination}

Kernel lipid was extracted as described by Zhang et al. (2017). In brief, 30 de-coated seeds were weighed after drying at $70{ }^{\circ} \mathrm{C}$ for 72 hours. The oil in the grounded kernels was then extracted in petroleum ether $\left(30-60{ }^{\circ} \mathrm{C}\right)$ using Soxhlet apparatus. The flask temperature was kept at $65{ }^{\circ} \mathrm{C}$ and the extraction lasted 12 hours. The oil was then separated from the petroleum ether phase using a rotary vacuum evaporator. After extraction, the grounded kernels were weighed again and the total crude lipid content was expressed as the percentage of oil on a DM basis.

\section{Potassium analysis}

For measuring potassium element in kernels, about $500 \mathrm{mg}$ frozen fresh kernels were mixed evenly with $9 \mathrm{~mL}$ concentrated sulfuric acid and $1 \mathrm{~mL}$ concentrated perchloric acid in a Kjeldahl flask. The flask was placed at room temperature overnight. The next day, the nutritional elements were released after approximately $30 \mathrm{~min}$ of digestion in a electric heating oven. After cooling under running water, the colourless extract was then passed through an ash-less filter paper and brought to a final volume of $100 \mathrm{~mL}$ with deionized water. To quantify kernel potassium, nutritional element extract was diluted 100-fold. The $\mathrm{K}$ concentration was determined using an atomic absorption spectrometer (Gharaghani et al. 2018). The wavelength $(776.49 \mathrm{~nm})$ was set by the WinLab32 AA Flame Control software.

\section{Acetyl coenzyme carboxylase (ACGase) activity}

The kernel ACCase activity from each development stage was measured with an enzymelinked immunosorbent assay kit according to the manufacturer's instructions. The preparation and quantification procedures were the same as described by Zhang et al. (2018b). In brief, the microtiter plates were pre-coated with an antibody specific to plant ACCase. After antibodyantigen interactions, signals were amplified and 
qualified. The colour change was measured spectrophotometrically at wavelength of $450 \mathrm{~nm}$ against the standard curve.

\section{Primary reserves assay}

To extract soluble sugars, $300 \mathrm{mg}$ kernels were homogenised in $10 \mathrm{~mL}$ deionised water. The homogenate was then transferred into a glass tube and kept in boiling water bath for $20 \mathrm{~min}$. After cooling under running water, the sugar extract was decanted and paper-filtered into a volumetric flask. The insoluble residue was again subjected to the same extraction procedure. The combined extract was then diluted with deionised water and brought to a volume of $25 \mathrm{~mL}$. The total soluble sugar content was measured using an anthrone colorimetric method with fructose as a standard (Zhang et al. 2017).

The quantification of kernel starch was adapted from Wu et al. (2020b). The residue remaining after sugar extraction was rehomogenised with $10 \mathrm{~mL}$ deionised water. After $15 \mathrm{~min}$ in boiling water bath, $2 \mathrm{~mL} \mathrm{HClO}_{4}$ $\left(9.2 \mathrm{~mol} \mathrm{~L}^{-1}\right)$ was added, followed by a further $15 \mathrm{~min}$ in the bath. The diluted supernatant was prepared by the same method above. The starch content was calculated through a standard curve, prepared using a starch solution of various concentrations.

The soluble protein was quantified according to Wu et al. (2020b). A total amount of $500 \mathrm{mg}$ de-coated seeds were homogenised in $5 \mathrm{~mL}$ extraction buffer containing $0.02 \mathrm{~mol} \mathrm{~L}^{-1}$ phosphate buffer ( $\mathrm{pH}$ 7.5). After centrifuging at $6000 \mathrm{rpm}$ for $15 \mathrm{~min}$ at $4{ }^{\circ} \mathrm{C}$, the supernatant was diluted well before measurement against bovine serum albumin as the standard.

\section{Statistical analysis}

Values were expressed as mean \pm standard deviation of three independent measurements. Excel was used to process the figures. One-way or two-way analysis of variance (ANOVA) was performed using SPSS 19.0 followed by Duncan's multiple range test. P-values less than 0.05 were considered to indicate significance within groups.

\section{RESULTS}

\section{Effects of foliar fertiliser treatments on photosynthetic activity in leaves}

Significant difference $(\mathrm{p}<0.05)$ was found within treatments for all photosynthetic activity indexes. Under the foliar application of $0.5 \mathrm{~g} \mathrm{~L}^{-1}$ potassium D-gluconate and the corresponding gluconate control $\left(0.676 \mathrm{~mL} \mathrm{~L}^{-1} \mathrm{D}\right.$-gluconic acid), the net photosynthetic rates at $57 \mathrm{DAF}$ were not significantly different with CK ( $p>0.05)$ (Table $1)$. As the foliar potassium concentration rose from $0.083 \mathrm{~g} \mathrm{~L}^{-1}$ (K1) to $0.666 \mathrm{~g} \mathrm{~L}^{-1}(\mathrm{~K} 2)$, a 44 and $69 \%$ increase were found, respectively, in the net photosynthetic rate and transpiration rate of the S. tonkinensis leaves. Plants under the two gluconate controls (G1 and G2) showed approximately similar photosynthetic rate and intercellular $\mathrm{CO}_{2}$ concentration $(\mathrm{p}>0.05)$.

With the exception of 77 and 97 DAF, little difference $(p>0.05)$ was found in the Chl a content between the K2 application and the CK (Figure 1A). The K2 resulted in boosted Chl a content which was 14 and 39\% higher than CK and G2 at 77 DAF, while 41 and $31 \%$ more Chl a was detected under $\mathrm{K} 2$ at $97 \mathrm{DAF}$ than CK and gluconate control (G2), respectively. Large

Table 1 Comparison of photosynthetic activity in leaves among treatments at 57 DAF (20 days after the first foliar spray onto Styrax tonkinensis trees)

\begin{tabular}{ccc}
\hline Treatment & $\begin{array}{c}\text { Photosynthetic rate } \\
\left(\mu \mathrm{mol} \mathrm{CO}_{2} \mathrm{~m}^{2} \mathrm{~s}^{-1}\right)\end{array}$ & $\begin{array}{c}\text { Transpiration rate } \\
\left(\mathrm{mmol} \mathrm{H}_{2} \mathrm{O} \mathrm{m}^{2} \mathrm{~s}^{-1}\right)\end{array}$ \\
\hline CK & $8.95 \pm 0.36^{\mathrm{a}}$ & $1.97 \pm 0.53^{\mathrm{a}}$ \\
$\mathrm{K} 1$ & $9.38 \pm 0.59^{\mathrm{a}}$ & $2.74 \pm 0.39^{\mathrm{b}}$ \\
$\mathrm{K} 2$ & $12.90 \pm 0.22^{\mathrm{b}}$ & $3.33 \pm 0.17^{\mathrm{b}}$ \\
$\mathrm{G} 1$ & $9.68 \pm 0.88^{\mathrm{ab}}$ & $2.05 \pm 0.58^{\mathrm{a}}$ \\
$\mathrm{G} 2$ & $10.60 \pm 0.76^{\mathrm{ab}}$ & $2.96 \pm 0.24^{\mathrm{b}}$ \\
\hline
\end{tabular}

Data are mean values of six plants from each treatment; different letters within treatments indicate significant difference $(\mathrm{p}<0.05)$ 
chlorophyll and carotenoid content gaps were observed between gluconate controls (G1 and G2) and other treatments (CK, K1 and K2) at 57 DAF (Figure $1 \mathrm{~A}-\mathrm{C}$ ). The $\mathrm{Chl} \mathrm{a} / \mathrm{b}$ ratio remained relatively steady under $\mathrm{K} 2$ at all developmental stages, whereas the $\mathrm{Chl} \mathrm{a/b}$ reached its nadir at 77 DAF under all other treatments (Figure 1D). The highest Chl $(\mathrm{a}+\mathrm{b}) /$ Car ratio (6.82) was found after treatment with $4 \mathrm{~g} \mathrm{~L}^{-1}$ potassium
D-gluconate (K2) at 77 DAF (Figure 1E). Values of the average ratio of $\mathrm{Chl} a / b$ and Chl $(\mathrm{a}+\mathrm{b}) / \mathrm{Car}$ under potassium D-gluconate (2.98 and 5.46 respectively) were higher than those under gluconate controls (2.69 and 5.10 respectively) and CK (2.82 and 5.24 respectively), which indicated that the foliar $\mathrm{K}$ application might increase the photosynthetic activity in S. tonkinensis.
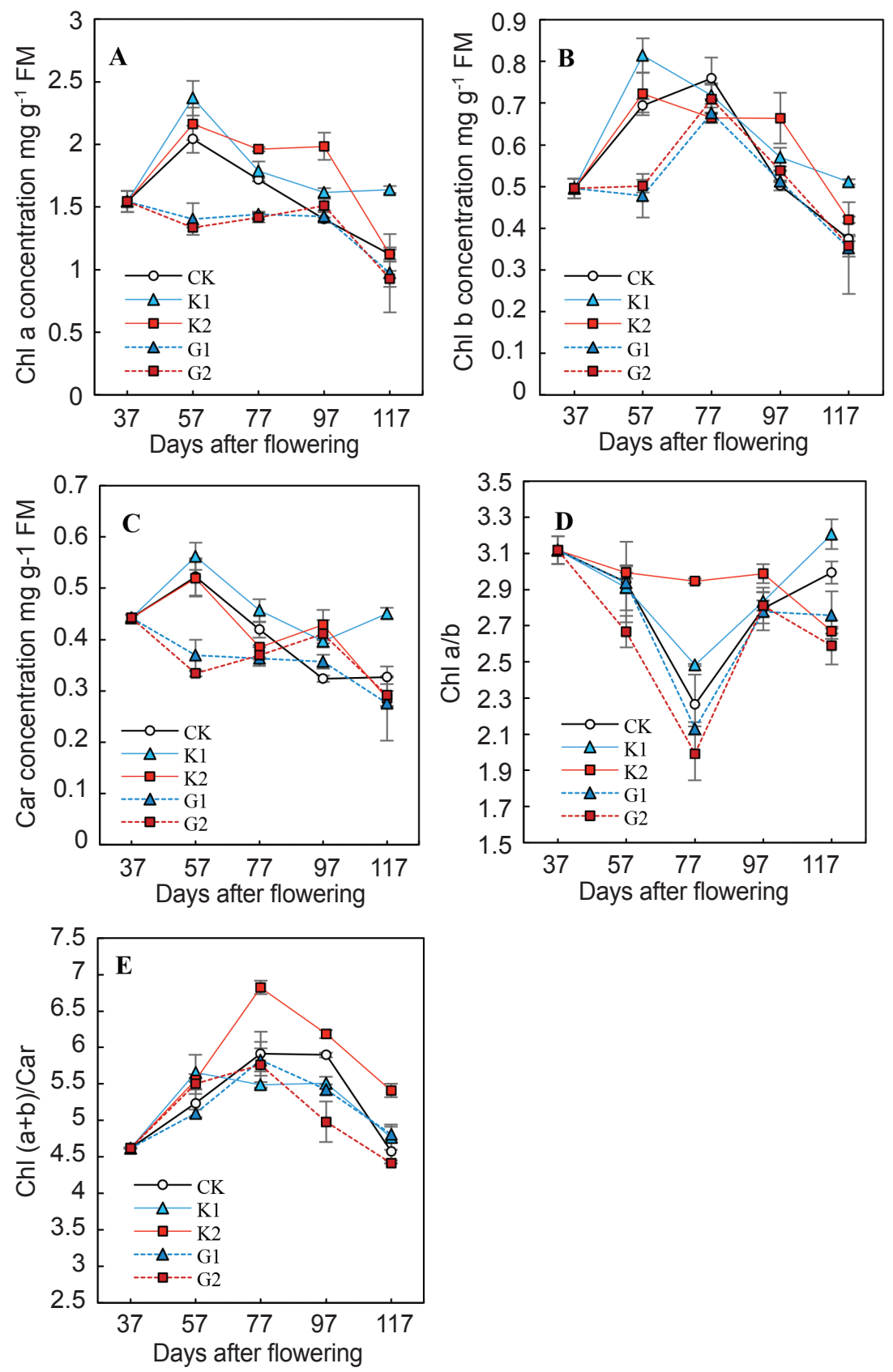

Figure 1 Dynamic chlorophyll and carotenoid concentration in Styrax tonkinensis leaves during fruit maturation under treatments; $\mathrm{A}=$ chlorophyll a concentration under $\mathrm{CK}, \mathrm{K} 1, \mathrm{~K} 2$, G1 and G2, B = chlorophyll b concentration under CK, K1, K2, G1 and G2, C= carotenoid concentration under CK, K1, K2, G1 and G2, D = chlorophyll a/b ratio under CK, K1, K2, G1 and G2, E = chlorophyll $(\mathrm{a}+\mathrm{b})$ /carotenoid ratio under CK, K1, K2, G1 and G2; $\mathrm{Chl}=$ chlorophyll, Car $=$ caratenoid, $\mathrm{FM}=$ fresh matter 
Effects of foliar fertiliser treatments on kernel yield and kernel oil content

The dynamics of the kernel dry weight evolved consistently among treatments at 37-77 DAF (Figure 2). After $77 \mathrm{DAF}, \mathrm{K} 2$ treatment caused the accumulation of more dry matter in S. tonkinensis kernels than in kernels growing in other foliar spray treatments, and the control $(\mathrm{p}<0.05)$. Compared with CK, a dramatic increase $(52 \%)$ in kernel dry weight, reaching $69.2 \mathrm{mg}$ per fruit, was detected at $137 \mathrm{DAF}$ when the $S$. tonkinensis trees were treated with foliar potassium fertiliser (4 $\mathrm{g} \mathrm{L}^{-1}$ potassium D-gluconate) during fruit maturation.

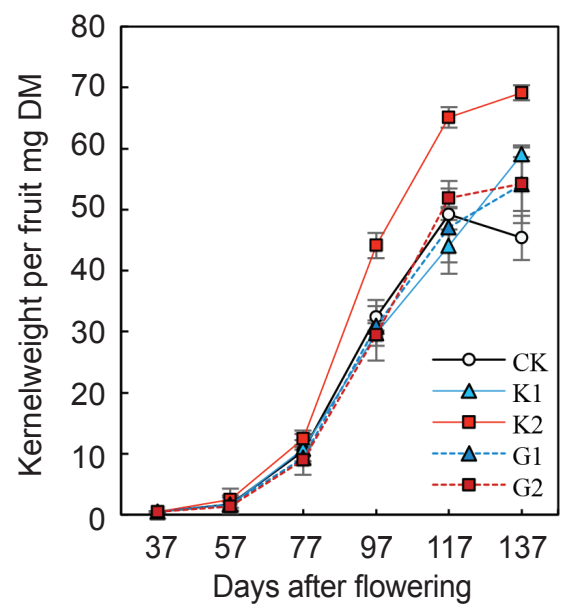

Figure 2 Kernel dry mass under CK, K1, K2, G1 and G2

To test whether the K application would alter the kernel oil accumulation process, the crude oil was analysed in kernels. In the CK, G1 and G2 treatments, kernel oil dynamics exhibited up-down patterns (Figure 3A). For CK, the peak concentration was found at $77 \mathrm{DAF}$, and a decreasing trend was then observed between 77 and 137 DAF (with a 13\% decrease). For G1 and G2, the oil concentrations increased gradually until 97 DAF (20 days after the CK peak), and then, decreasing trends were detected for the next forty days, with a 19 and $27 \%$ decline, respectively. Interestingly, kernel oil synthesis was altered after the foliar $\mathrm{K}$ spray, and no oil accumulation rate reduction was found during the mid-late stage of $S$. tonkinensis seed filling. Linear regressions could be constructed for the dynamics of kernel lipid concentrations under potassium treatments (for $\mathrm{K} 1, \mathrm{r}^{2}=0.949$, $\mathrm{p}<0.01$; for $\left.\mathrm{K} 2, \mathrm{r}^{2}=0.906, \mathrm{p}<0.01\right)$. The change in the oil per kernel over time displayed a sigmoidal pattern for most treatments (Figure 3B), and the total crude lipid per kernel was greatly promoted in the Kapplications, where it was $42 \%$ (K1) and $72 \%$ (K2) higher than CK at 137 DAF ( $<<0.05)$. The kernel lipid composition of all treatments at 137 DAF was then further investigated. As shown in Figure 3C, 4.4-6.3\% non-fatty-acid lipid (non$\mathrm{FA}$ ) was detected in CK, $\mathrm{K} 1$ and G1, whereas $9.2 \%$ non-FA was found in K2. Thus, in the one-way ANOVA, no significant difference $(p>0.05)$ was detected in the fatty acid concentration among K1, K2 and CK. However, when the kernel dry mass was considered, the total fatty acid content in each kernel was boosted after the foliar potassium spray, with a 39 and a $63 \%$ increase for K1 and K2, respectively (Figure 3D). Statistically, there was no significant difference within treatments among all fatty acids $(p>0.05)$. In CK, the dynamics of kernel ACCase activity followed an M-shaped trend. Peaks were observed along with the lipid accumulation process, at 57 and 97 DAF (Figure 3E). In other treatments, the ACCase activity expressed a single peak between 57 and 77 DAF.

\section{DISCUSSION}

\section{Foliar K treatments may promote photosynthesis in leaves and improve fruit dry mass}

In the present study, foliar spray of $\mathrm{K}$ fertiliser (potassium D-gluconate, which is exclusive from other essential mineral elements such as nitrogen, phosphorus and sulphur) was applied to determine its effect on fruit growth and kernel lipid synthesis in S. tonkinensis. Numerous researchers have found that foliar applications of potassium had a positive effect on photosynthesis by stimulating the pigments and enzyme activities, which consequently encouraged the vegetative and reproductive growth in plants (Egilla et al. 2005, Jabeen et al. 2011). In the field experiment, the content of chlorophyll in leaves showed a rise and fall pattern under all treatments (Figure 1). The $\mathrm{K}$ spray improved the net photosynthesis rate (Table 1), as well as chlorophyll and carotenoid average values (for total Chl, CK: $2.12 \mathrm{mg} \mathrm{g}^{-1}$ fresh matter (FM), K-gluconate: $2.40 \mathrm{mg} \mathrm{g}^{-1}$ FM, gluconate control: $1.86 \mathrm{mg} \mathrm{g}^{-1} \mathrm{FM}$; for Car, CK: $0.40 \mathrm{mg} \mathrm{g}^{-1} \mathrm{FM}$, K-gluconate: $0.44 \mathrm{mg} \mathrm{g}^{-1}$ 

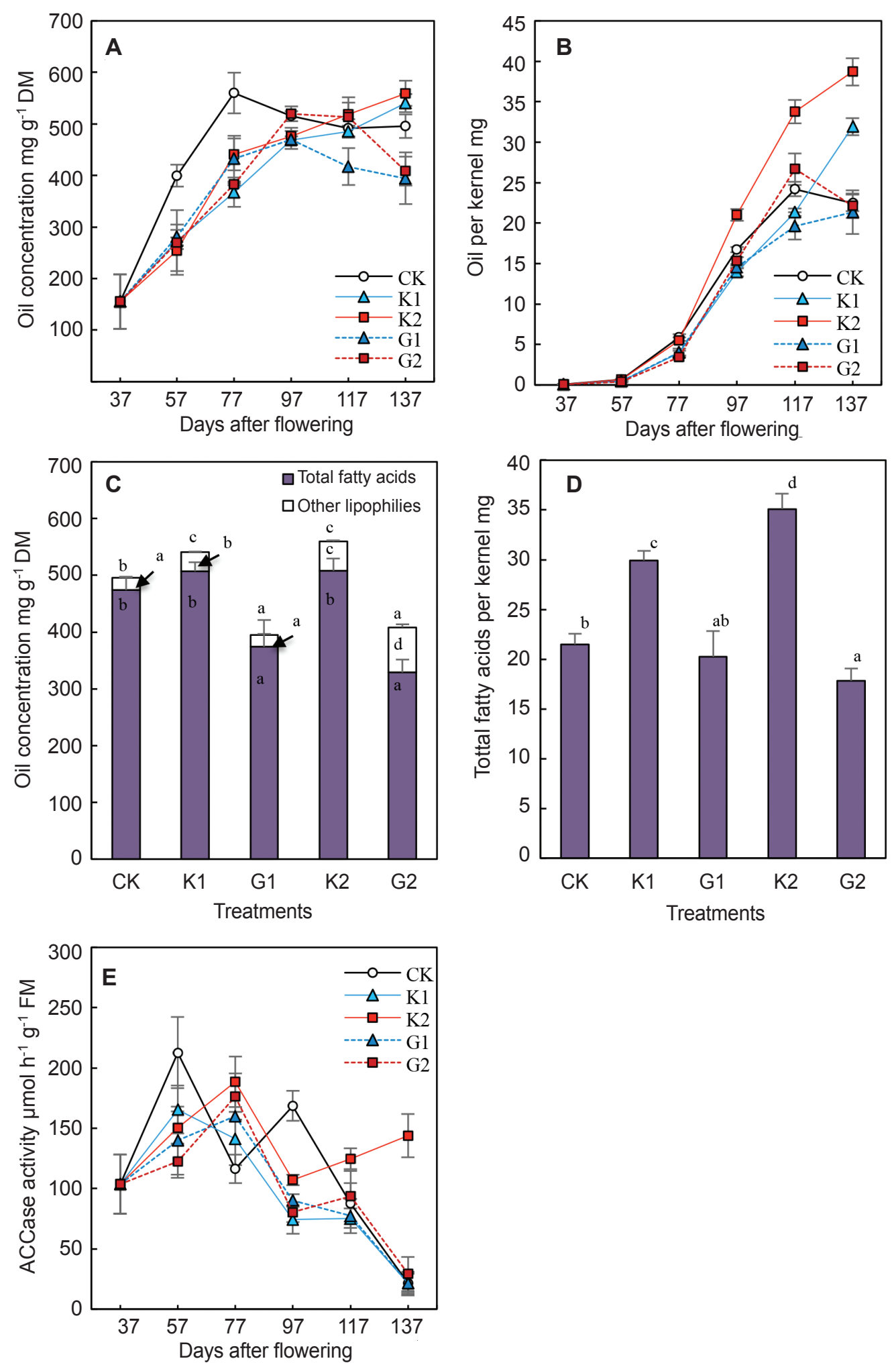

Figure 3 Lipid synthesis in developing Styrax tonkinensis kernels under different foliar treatments; $\mathrm{A}=$ oil concentration in kernels, $\mathrm{B}=$ oil content per kernel, $\mathrm{C}=$ total fatty acids and other lipophilic composition at $137 \mathrm{DAF}$; different letters within treatments indicate significant difference $(\mathrm{p}<0.05)$ for total fatty acids (letters inside black bars), or other lipophilic (letters inside white bars), or total crude oil (i.e, total fatty acids + other lipophilic; letters above white bars), and different letters within treatments indicate significant difference $(\mathrm{p}<0.05) ; \mathrm{D}=$ total fatty acids content per kernel at $137 \mathrm{DAF}, \mathrm{E}=$ acetyl coenzyme carboxylase (ACCase) activity dynamics under CK, K1, K2, G1 and G22, DM = dry matter 
FM, gluconate control: $0.36 \mathrm{mg} \mathrm{g}^{-1} \mathrm{FM}$ ) (Figure 1). It has been shown that the higher $\mathrm{Chl} a / b$ ratio increased the PSII performance (Li et al. 2009). Furthermore, the elevated Chl $(a+b) /$ Car would lead to higher absorption efficiency at the blue and red spectra (Zhang et al. 2018a). The pigment evidences suggest that the activity of photosynthetic light reaction in leaves was enhanced by $\mathrm{K}$ spray. The present results showed that $4 \mathrm{~g} \mathrm{~L}^{-1} \mathrm{~K}$-gluconate (K2) markedly enhanced the dry matter accumulation rates in the kernels (Figure 2). These findings are in line with previous studies. In chervil plant (Anthriscus cerefolium), K fertiliser increased herb and essential oil yield as well as photosynthetic pigments compared with control (El Gendy et al. 2015). Foliar spray of potassium increased the maize yield under rainfed conditions (Anees et al. 2016). Researchers have reached a consensus that the increment in biological yield (i.e., grain number, grain weight, etc.) could be due to the role of potassium, in both boosting of leaf photosynthetic activity and availability of photosynthates for translocation from leaves (source) to fruits (sink).

\section{$K$ concertation affects oil accumulation in kernels}

During S. tonkinensis kernel development, potassium had a significant positive correlation with oil concentration (Wu et al. 2019). The potassium concentration in kernels were not elevated under the spray of foliar $\mathrm{K}$ fertilisers, and the total fatty acids concentrations under $\mathrm{K}$ treatments had little difference $(p>0.05)$ when compared with those of CK at 137 DAF (Figure $3)$. The enhancement of total oil content per kernel is due to the positive response of fruit dry mass to K treatments, which coincides with most previous studies (Romheld \& Kirkby 2010, El Gendy et al. 2015, Helmy \& Mohamed 2014). Other primary assimilates (i.e., starch, sugar and protein) increased in each $S$. tonkinensis kernel as well (Figure 4A-E). Unexpectedly, the foliar K spray affected the potassium and lipid accumulation patterns in kernels (although the final oil concentration was not altered). Specifically, for CK, the potassium concentration dynamics had a $40 \%$ decrease at 77-97 DAF before it rose markedly again during the next 20 days, whereas the $\mathrm{K}$ concentration was well maintained (3.4-3.8 $\mathrm{mg} \mathrm{g}^{-1} \mathrm{FM}$ ) during the period from 77 to $117 \mathrm{DAF}$ under K2 treatment (Figure S2). Generally, the massive potassium concentration declines and oil accumulation rate reduction at the mid-late stage can be alleviated under $\mathrm{K}$ treatments, nevertheless, the final oil concentration was not affected. However, the question remains as how $\mathrm{K}$ affect lipid biosynthesis process.

\section{Potassium might affect carbon partitioning among kernel primary assimilates}

There is solid evidence that lipid storage is influenced by other cell metabolic pathways (Klaus et al. 2004, Weselake et al. 2009). Overexpression of Escherichia coli ADP-glucose pyrophosphorylase in both Brassica napus and Arabidopsis thaliana seeds resulted in the diversion of carbon precursors from lipid toward starch (Boddupalli et al. 1995, Lin et al. 2006). Consequently, a major increase in starch content and a decrease in oil content was observed. In the present study, the carbohydrate (sugar + starch) proportion among primary metabolites increased from 57 to $77 \mathrm{DAF}$ (Figure 4F-J) and oil accumulation rate from 37 to 77 DAF (Figure 3A). Values from highest to lowest were CK, K2 and G2. These results showed that when more carbon accumulates in carbohydrates, the oil assembly speed would slow down. Given that cell carbon can flow into either the pyruvate pool (substrate for fatty acids biosynthesis) in plastids or other carbohydrate, the precursor competition among carbon reserves may play a role in manipulating the oil accumulation process.

After further investigation, it was found that kernel $\mathrm{K}$ was closely related to the oil ratio, among all primary reserves $(\mathrm{p}<0.05)$ (Figure $5)$. The finding prompted the authors to assume that potassium may have an impact on precursor partitioning among carbon assimilation during kernel maturation, which regulates oil accumulation rate. This assumption, however, needs to be further examined.

\section{Study limitations}

Photosynthesis data should be measured more than once at 57 DAF, which would facilitate the evaluation on photosynthetic behavior in leaves under different K sprays. The total yield per plant is agronomically important. Unfortunately, the 

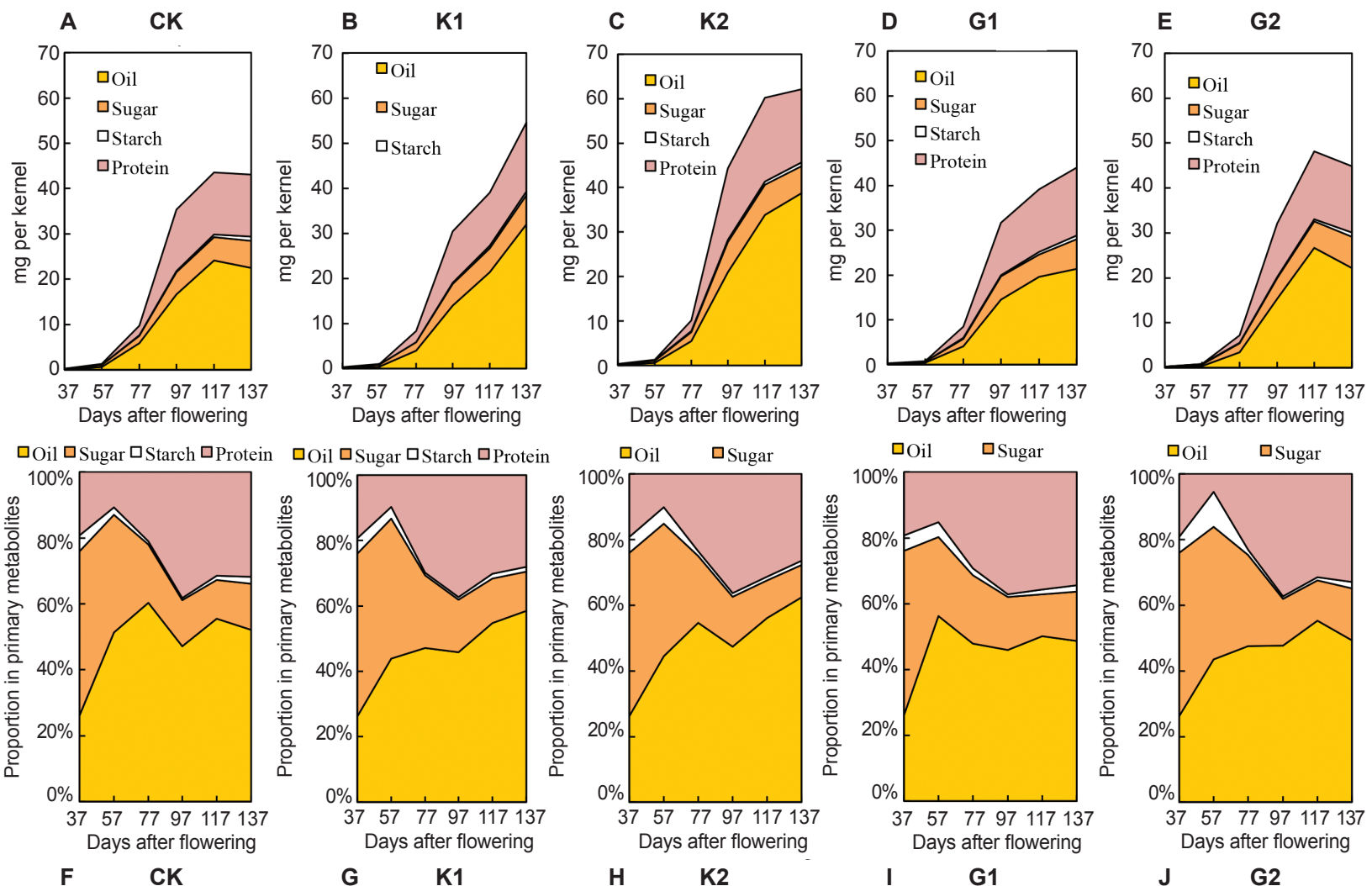

Figure 4 Reserves (lipid, starch, sugar and protein) total content per kernel (A-E) and concentration dynamics (F-J) in Styrax tonkinensis under different treatments

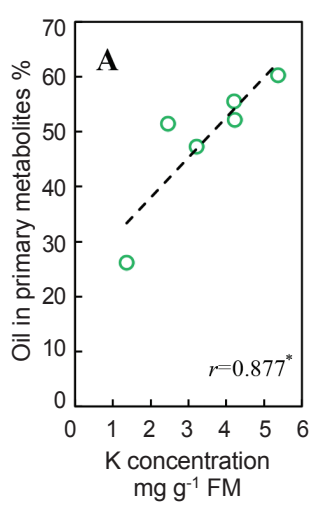

CK

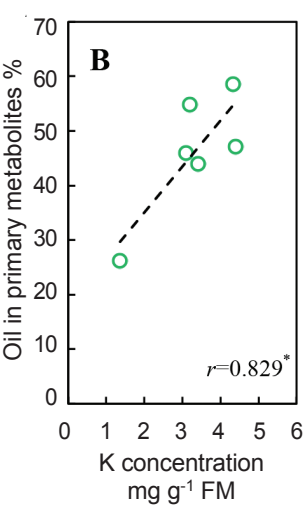

K1

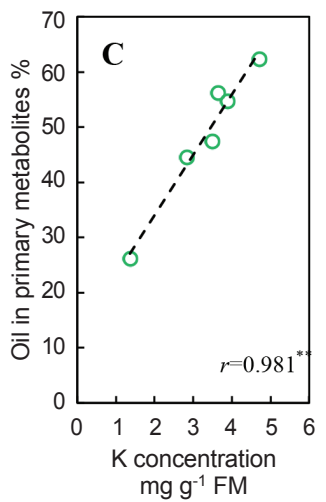

K2

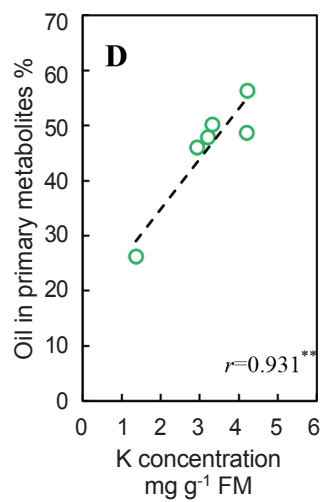

G1

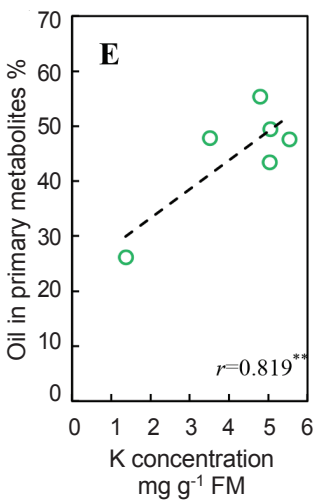

G2

Figure 5 Relation between kernel $\mathrm{K}$ and oil proportion among kernel reserves under different treatments (A-E); *represents significance at 0.05 level, and **represents significance at 0.01 level

total yield of seeds, kernel oil or kernel potassium per tree were unable to be included in this paper, since the fruits were sampled over time. Potassium fertilisers in higher concentrations can be discussed in further studies. In addition, advanced proteome or transcriptome analysis can be conducted to profoundly disclose the role of $\mathrm{K}$ in lipid biosynthesis in $S$. tonkinensis kernels.

\section{CONCLUSIONS}

For the first time, potassium fertiliser was applied by foliar spray during $S$. tonkinensis fruit maturation season, to study the effects of foliar K on lipid biosynthesis in the kernels. During S. tonkinensis kernel development, foliar potassium fertiliser increased photosynthesis 
and promoted the transport of assimilates to the sinks. Compared with CK, the final kernel oil concentration was not boosted under all treatments. However, major increases in the lipid yield per kernel were found under $\mathrm{K} 1\left(0.5 \mathrm{~g} \mathrm{~L}^{-1}\right.$ potassium gluconate) and $\mathrm{K}^{2}\left(4 \mathrm{~g} \mathrm{~L}^{-1}\right.$ potassium gluconate) treatments. The findings suggest that a foliar K spray, at a suitable concentration during fruit development, could be considered to increase seed and oil yields.

\section{ACKNOWLEDGEMENTS}

The authors would like to thank XiaoyueJi from Advanced Analysis Testing Center, Nanjing Forestry University for the GC-MS technical assistance and the American Journal experts (https://www.aje.com/) for language improvement.

\section{REFERENCES}

Anees MA, Abid A, Shakoor U, Faroog A, Hasnain Z \& Hussain A. 2016. Foliar applied potassium and zinc enhances growth and yield performance of maize under rainfed conditions. International Journal of Agriculture and Biology 18: 1025-1032.

Baud S \& Lepiniec L. 2010. Physiological and developmental regulation of seed oil production. Progress in Lipid Research 49: 235-249.

Boddupalli SS, Stark DM, Barry GF \& Kishore GM. 1995. Effect of overexpressing ADP-Glc-pyrophosphorylase on the oil biosynthesis in canola. Pp 102 in Ohlrogge JB \& Jaworski JG (eds) Biochemistry and Molecular Biology of Plant Fatty Acids and Glycerolipids Symposium. 1-4 June 1995, South Lake Tahoe.

Chen W, Li L, Liu G et al. 2015. Response surface methodology to optimize production of biodiesel from Styrax tonkinensis. Guangzhou Chemistry and Industry 43: 46-49.

Egilla JN, Davies FT \& Boutton TW. 2005. Drought stress influences leaf water content, photosynthesis, and water-use efficiency of Hibiscus rosasinensis at three potassium concentrations. Photosynthetica 43: 135-140.

El Gendy AG, El Gohary AE, Omer EA et Al. 2015. Effect of nitrogen and potassium fertiliser on herbage and oil yield of chervil plant (Anthriscus cerefolium L.). Industrial Crop and Products 69: 167-174.

Gotore T, Murepa R \& Gapare WJ. 2014. Effects of nitrogen, phosphorus and potassium on the early growth of Pinus patula and Eucalyptus grandis. Journal of Tropical Forest Science 26: 22-31.

Gharaghani A, JaVarzari AM \& Vahdati K. 2018. Kaolin particle film alleviates adverse effects of light and heat stresses and improves nut and kernel quality in Persian walnut. Scientia Horticulturae 239: 35-40.

Harwood JL, Woodfield HK, Chen G \& Weselake RJ. 2017. Modification of oil crops to produce fatty acids for industrial applications. Pp 187-236 in Moghis UA (ed) Fatty Acids-Chemistry, Synthesis and Applications. Academic Press, Elsevier, Massachusetis.

Helmy AM \& Mohamed FR. 2014. Yield quality parameters and chemical composition of peanut as affected by potassium and gypsum applications under foliar spraying with boron. Communications in Soil Science and Plant Analysis 45: 2397-2412.

Hieu PS, Thuy VH \& Thuan PD. 2011. Main characteristics of statistical data and the statistical system for wood and wood-processing products in Vietnam. Small Scale Forestry 10: 185-198.

JABEEN N \& AHMAD R. 2011. Foliar application of potassium nitrate affects the growth and nitrate reductase activity in sunflower and safflower leaves under salinity. Notulae Botanicae Horti Agrobotanici Cluj Napoca 39: 172-178.

Kamel SM, Mahfouz HM, Blal HA, Said M \& Mahmoud MF. 2016. Effects of salicylic acid elicitor and potassium fertiliser as foliar spray on canola production in the reclaimed land in Ismailia Governorate, Egypt. CercetariAgronomice in Moldova 49: 81-89.

Klaus D, Ohlrogge JB, Neuhaus He \& Dörmann P. 2004. Increased fatty acid production in potato by engineering of acetyl-CoA carboxylase. Planta 219: 389-396.

Li Y, Zhu F, Wang J, Miki N, Sakamotto K \& Yoshikawa K. 2009. Seasonal changes of photosynthetic characteristics and pigment composition of Sabina vulgaris Ant. under water stress. Acta Ecologica Sinica 29: 4346-4352.

Lin Y, Ulanov AV, Lozovaya V et al. 2006. Genetic and transgenic perturbations of carbon reserve production in Arabidopsis seeds reveal metabolic interactions of biochemical pathways. Planta 225: 153-164.

Liu J, Hua W, Yang H et al. 2014. Effects of specific organs on seed oil accumulation in Brassica napus L. Plant Science 227: 60-68.

Marschner P. 2012. Marschner's Mineral Nutrition of Higher Plants. Third Printing Revised. Academic Press, London.

Matsuo MU, Sujan KC, Hirota I, Kojima M, Yoshida M \& Үамамото H. 2016. Utilisation of Styrax tonkinensis wood in Laos and its physical properties. Journal of Tropical Forest Science 28: 298-307.

Ohlrogge JB \& Jaworski JG. 1997. Regulation of fatty acid synthesis. Annual Review of Plant Biology 48: 109-136.

Pinyopusarerk K. 1994. Styrax tonkinensis: Taxonomy, Ecology, Silviculture and Uses. ACIAR Technical Reports No.31. CPN Publication, Canberra.

PORRA RJ. 2005. The chequered history of the development and use of simultaneous equations for the accurate determination of chlorophylls a and b. Pp 633-640 in Beatty JT et al. (eds) Discoveries in Photosynthesis. Springer-Verlag, New York.

RomHeld V \& Kirkby EA. 2010. Research on potassium in agriculture: Needs and Prospects. Plant and Soil 335: 155-180.

Shi C, Li Y, Zhu G, Liu X, Yang L \& Sheng W. 2013. Seed oil production rate and fatty acid content of Styrax tonkinensis during seed maturation. Jounral of Zhejiang Agriculture and Forestry University 30: 372-378. 
Weselake RJ, TAYlor DC, RAHMAn MH et AL. 2009. Increasing the flow of carbon into seed oil. Biotechnology Advances 27: 866-878.

Wu JG, Shi CH \& Zhang HZ. 2006. Partitioning genetic effects due to embryo, cytoplasm and maternal parent for oil content in oilseed rape (Brassica napus L.). Genetics and Molecular Biology 29: 533-538.

Wu Q, Zhang Z, Peng H, Wu Y \& Yu F. 2019. The nutrient distribution in the continuum of the pericarp, seed coat, and kernel during Styrax tonkinensis fruit development. Peer J 7: e7996.

Wu Q, Zhao X, Chen C, Zhang Z \& Yu F. 2020a. Metabolite profiling and classification of developing Styrax tonkinensis kernels. Metabolites 10: 21.

Wu Q, Cao Y, Zhao X, Zhang Z \& Yu F. 2020b. A comparative study of seed reserve accumulation in five Styrax species with potential for biofuel production. TreesStruction and Function 34: 891-902.

Xiong B, Zhang Z \& Dong S. 2018. Biodiesel from Lindera glauca oil, a potential non-food feedstock in
Southern China. Industrial Crop and Products 122: 107-113.

Xu L \& YU F. 2015. Corolla structure and fragrance components in Styrax tonkinensis. Trees-Struction and Function 29: 1127-1134.

Zhang Z, Luo Y, WANG X \& Yu F. 2018a. Fruit spray of 24-Epibrassinolide and fruit shade alter pericarp photosynthesis activity and seed lipid accumulation in Styrax tonkinensis. Journal of Plant Growth Regulation 37: 1066-1084.

Zhang Z, Luo Y, Wang X \& Yu F. 2018b. Quantitative spatiotemporal oil body ultrastructure helps to verify the distinct lipid deposition patterns in benzoin endosperm and embryo cells. Forests 9: 265.

Zhang Z, WANG X, LuO Y \& Yu F. 2017. Carbon competition between fatty acids and starch during benzoin seeds maturation slows oil accumulation speed. TreesStructure and Function 31: 1025-1039. 
Table S1 Concentration of foliar fertiliser applied for Styrax tonkinensis plants in each treatment and the corresponding potassium and gluconate concentrations

\begin{tabular}{ccccc}
\hline & \multicolumn{3}{c}{ Treatments } & \multicolumn{3}{c}{ Concentrations } \\
\cline { 3 - 4 } & Wh & Foliar fertiliser & Potassium & Gluconate \\
\hline K1 & Potassium D-gluconate & $0.5 \mathrm{~g} \mathrm{~L}^{-1}$ & $\mathrm{NA}$ & $\mathrm{NA}$ \\
K2 & Potassium D-gluconate & $4.0 \mathrm{~g} \mathrm{~L}^{-1}$ & $0.083 \mathrm{~g} \mathrm{~L}^{-1}$ & $0.417 \mathrm{~g} \mathrm{~L}^{-1}$ \\
G1 & D-gluconic acid & $0.676 \mathrm{~mL} \mathrm{~L}^{-1}$ & $\mathrm{NA} \mathrm{g} \mathrm{L}^{-1}$ & $3.333 \mathrm{~g} \mathrm{~L}^{-1}$ \\
G2 & D-gluconic acid & $5.403 \mathrm{~mL} \mathrm{~L}^{-1}$ & $\mathrm{NA}$ & $0.417 \mathrm{~g} \mathrm{~L}^{-1}$ \\
\hline
\end{tabular}

$\mathrm{NA}=$ not applied
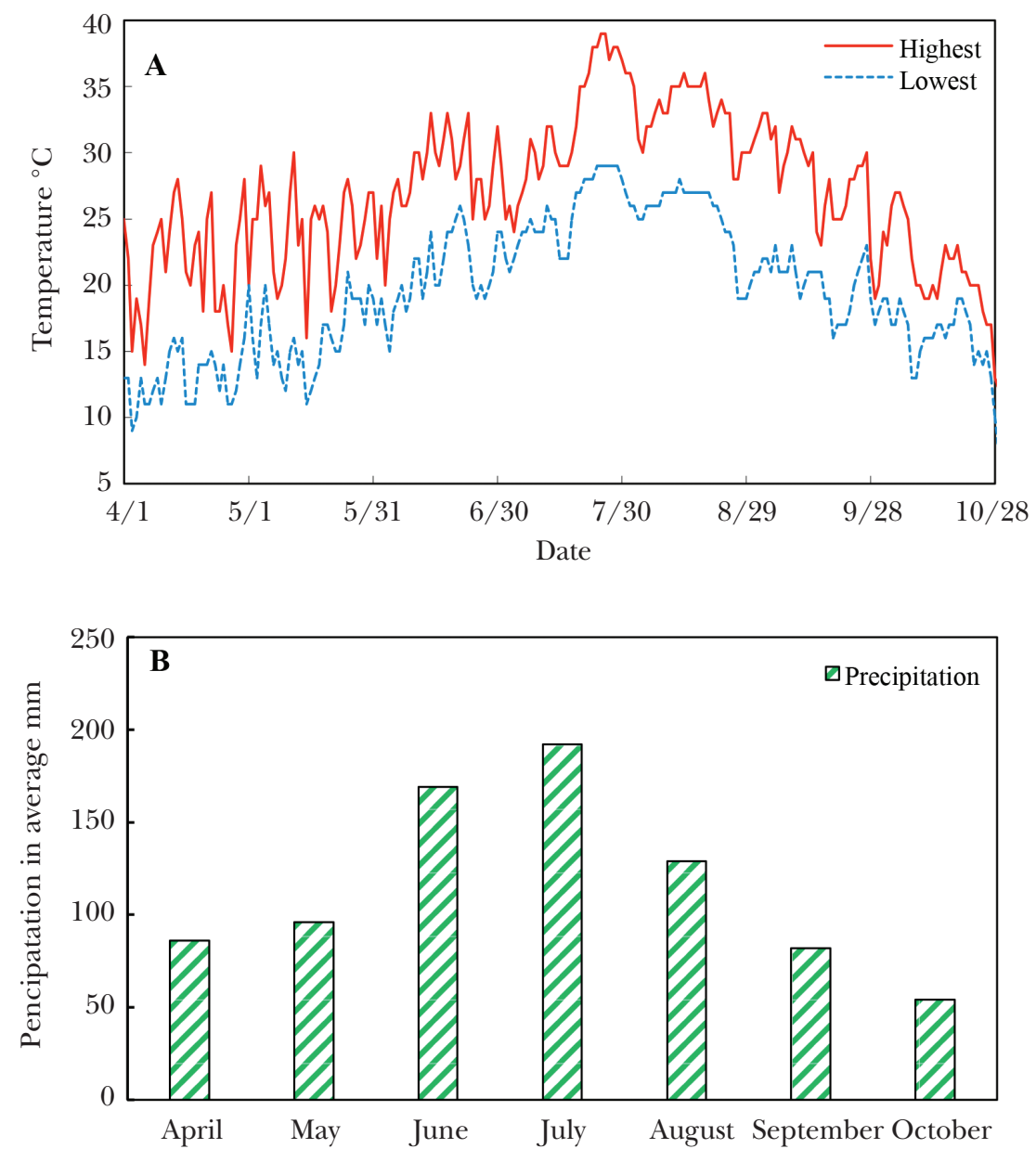

Figure S1 Meteorological data recorded at Luhe District, Nanjing, China from April to October, 2016; $\mathrm{A}=$ highest and lowest temperature daily, $\mathrm{B}=$ average precipitation monthly; data acquired from the public service website of Chinese Meteorological Administration (http://www.weather.com.cn/) 


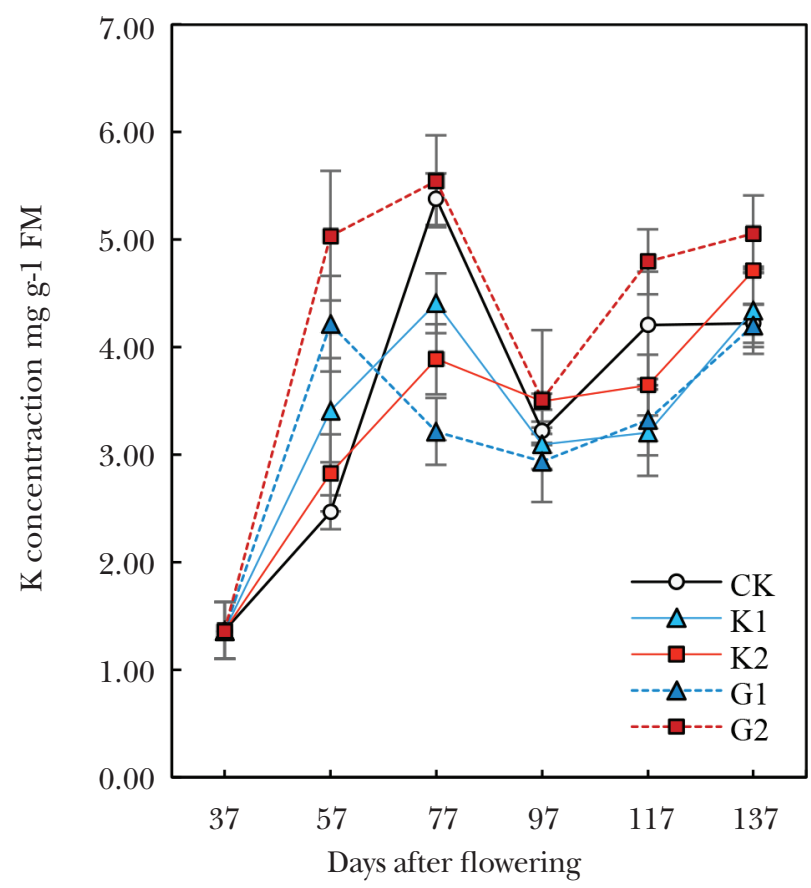

Figure S2 Potassium concentration dynamics in developing Styrax tonkinensis kernels after foliar spray of K1, K2, G1, G2 and CK 